Portland State University

PDXScholar

$5-1973$

\title{
Agonistic Behavior and Dominance in Townsend's Chipmunks (Eutamias townsendii)
}

Paul Evan Sherman

Portland State University

Follow this and additional works at: https://pdxscholar.library.pdx.edu/open_access_etds

Part of the Biology Commons

Let us know how access to this document benefits you.

\section{Recommended Citation}

Sherman, Paul Evan, "Agonistic Behavior and Dominance in Townsend's Chipmunks (Eutamias townsendii)" (1973). Dissertations and Theses. Paper 2039.

https://doi.org/10.15760/etd.2038

This Thesis is brought to you for free and open access. It has been accepted for inclusion in Dissertations and Theses by an authorized administrator of PDXScholar. Please contact us if we can make this document more accessible: pdxscholar@pdx.edu. 
AN ABSTRACT OF TIE THESIS OF Paul IVan Shemen for the iwaster of Science in 3ioloct presented May 18,1973 .

Title: Agonistic Dehavior and Dominance in Townsend's Chiomuns (Eutamias townsendii).

APPROVED BY NEIBERS OF THE THESIS CORIIITMEE:

Richard B. Forbes, Chairman

John H. Wirtz $Y$

Robert 0 . Tinnin

Acoinistic behavior and dominance are described for ceptivo Townsond's chipmunks (Eutomias townsendii). A total of 10,739 oncountors was recorded; 6441 (59.9\%) vrore agonistic. Chascs $(58.5 \%)$ and displacements $(30.8 \%$ ) werc the predominant aronistic behaviors; threats $(6.8 \%$ ) and firhts (4.15) were relatively rare.

Stable, non-triancular hierarchies were rapidly established in 11 of the 12 rroups of chipmunls obscrved; the presence of individuals of equal rank in some froups 
procluded strict lincaritu. Doriuance positions did not change within a group, but roversals in raul and changos Prom equal to dominant-subordinate relationships occurred when the nembership of Groups was changed. One hierarchy existed for both sexes; neither sex was consistontly dominent. Experience and individual differences in activity and argressiveness were nore irmortant deterninants of an animal's position in the hierarchy than were sex or size. No correlation was found between rank and cncounter frequency, nor was closeness of rank strongly correlatcd with hioh nunbers of aronistic encountors botween any two chipmuns. The froquencies of recognitory and sezual behevior were inversely related to the frequency of aronistic behavior botrreen pairs of aninals.

Ritualized threats and appeasement behaviors did not roplace overt ajoression in estabiished hierarchies. Henbors of hierarchies showed neither a reduction in numbers of agonistic cncounters, nor temporal changes in frequency of the different types of aronistic behavior. Aonistic cncouiters increasea in Irequency from Aurust to Docomber, but scasonal veriations wore much snaller than variations anons the groups. Although dorninence reduced neither the frequency of afonistic behevior nor the time and enorfy spent in chasing, it may be advantaceous in curtailing hampul confrontations and exhancing the establishnent of tolerance anong some individuals. 
AGONISTIC BEHAVIOR AND DOMINATVE IN TOWNSEND'S CHIPMUNKS (EUTAMITAS TOWMSENDII)

\author{
by \\ PAUI EVAIN SHERMAN
}

A thesis submitted in partial fulfillment of the requirements for the degree of

\author{
MASTER OF SCIENCE \\ in \\ BIOIOGY
}

Portland State University

1973 
TO THE OFFICL OF GRADUHTE STUDIES AND RESEARCH:

The members of the Committee approve the thesis of Paul Evan Sherman presented May 18,1973.

Richard B. Forbes, Chairman

Jonnth. Wirtz

Robert 0. Tinnin

APPROVED:

Farl Fisher Jr., Head, Department of Biology 7

DEvid T. Clark, Dean of Graduate Studies and Research 


\section{ACKNOWIEDAGIENTS}

I wish to express gratitude to Dr. Richard B. Forbes for critically reviewing the manuscript and lending his expertise to its preparation; to Drs. John H. Wirtz and Robert 0 . Tinnin for reading the paper and serving on the thesis committee; and to my wife, Jill, who provided numerous forms of assistance throughout the study. 
TABIE OF CONTENTS

PAGE

ACKNOWIEDGNENTS $\ldots \ldots \ldots \ldots \ldots \ldots \ldots \ldots \ldots \ldots \ldots$ ii

IIST OF FIGURES $\ldots \ldots \ldots \ldots \ldots \ldots \ldots \ldots \ldots \ldots \ldots \ldots$ v

INTRODUCTION $\ldots \ldots \ldots \ldots \ldots \ldots \ldots \ldots \ldots \ldots \ldots$

NETHODS OF STUDY $\ldots \ldots \ldots \ldots \ldots \ldots \ldots \ldots \ldots \ldots$

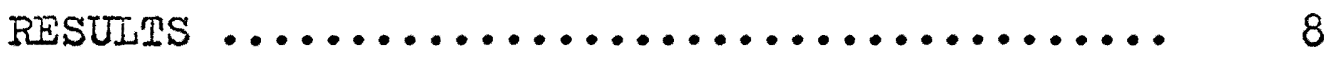

I Patterns of Agonistic Behavior ...... 8

II Dominance Hierarchy Structure ...... 15

II Hierarchy Development ........... 24

IV SeasonaI Variation ............. 28

$\checkmark$ Intergroup and Individual Variation .. 33

DISCUSSION $\ldots \ldots \ldots \ldots \ldots \ldots \ldots \ldots \ldots \ldots \ldots \ldots \ldots \ldots \ldots$

CONCLUSIONS $\ldots \ldots \ldots \ldots \ldots \ldots \ldots \ldots \ldots \ldots . \ldots \ldots$

REFERENCES $\ldots \ldots \ldots \ldots \ldots \ldots \ldots \ldots \ldots \ldots \ldots \ldots \ldots \ldots \ldots \ldots \ldots \ldots \ldots \ldots$ 


\section{IIST OF FIGURES}

FIGURE

PAGE

1 Results of agonistic encounters in six groups observed between August 1 and October 8, 1972. Wins are recorded vertically and losses horizontally ...... I6

2 Results of agonistic encounters in six groups observed between October 9 and December 31, 1972. Wins are recorded vertically and losses horizontally

3. Frequency of agonistic encounters through time in six cage groups observed between August 4 and October 6, 1972. The dot on the ordinate represents the encounter rate during the first day ............ 26

4 Frequency of agonistic encounters through time in three cage groups observed between October 9 and December 19, 1972. The dot on the ordinate represents the encounter rate during the first day

5 Total agonistic encounters in all cages during successive time intervals 
vi

FIGURE

PAGE

6 Seasonal variations in overall agonistic

encounters (average encounters per hour

in successive 15 day intervals)........ 31

7 Seasonal variation in frequencies of four

types of agonistic behavior in

successive 15 day intervals .......... 32

8 Frequency of agonistic encounters in 12 cage

groups $\ldots \ldots \ldots \ldots \ldots \ldots \ldots \ldots \ldots . \ldots \ldots$ 


\section{INTRODUCTION}

Intraspecific fighting and aggressive behavior are common phenomina in many animals, yet have potentially deleterious effects. Injury or death, energy and time expenditure, and increased vulnerability to predation are all manifestations of fighting, thus making its restriction of considerable importance (Tinbergen 1965). Territoriality restricts fighting by dispersing members of a species more widely, and conferring an aggressive advantage to a resident over an intruder. Fighting is also reduced by the establishment of a dominance hierarchy. Through recognition and memory, subordinate animals learn to avoid or relinquish position to dominant individuals, and to dominate those of lower rank. In many species, an initial period of overt conflict is supplanted by a preponderance of ritualized threat behaviors in addition to an overall reduction in agonistic behavior. The function and selective advantage of this occurrence is the maintenance of order by rank without suffering the effects associated with active combat.

Social dominance and agonistic behavior in Sciuridae have been widely studied (Anthony, Bronson, Farentinos, Gordon, King, Sheppard and Yoshida, and Yeaton). Despite 
the suitability of chipmunks for behavioral studies, investigations of these animals have been relatively meager. The eastern chipmunk (Tamias) has been the subject of many more papers than has its more widely distributed and variable western counterpart (Eutamias). Descriptive field studies on Tamias have been done by Fraleigh (1929), Burt (1940), Yerger (1953), and Dunford (1970) among others. Condrin (1936) and Wolfe (1966) have studied captive Tamias striatus.

Descriptive field work on agonistic behavior has been done for Eutamias in general (Gordon 1936, 1943) and for E. amoenus (Broadbooks 1958, 1970). Interspecific agonistic behavior has been investigated by Brown (1970), Heller (1970), and Sheppard (1971). Brand (1970) devoted a portion of his study on chipmunks in California to agonistic behavior and dominance in E. townsendii. Quantitative information on agonistic encounters and dominance relationships was included in studies by Condrin (1936) and Wolfe (1966) on Tamias, and by Brand (1970) on Eutarnias. Brown (1971), Brand (1970), and others indicated that agonistic behavior in the field was qualitatively similar to that of captive animals.

The present study categorizes and describes agonistic behaviors and dominance hierarchies in captive Qutamias townsendii townsendii. A qualitative and quantitative analysis of the observed behavior patterns 
related to the formation and development of dominance relationships is presented. 


\section{METHODS OF STUDY}

Twelve groups of four chipmunks (E. townsendij) each were used in the study, which began I August 1972 and ended I January 1973. A total of 230 hours of observation was logged. The chipmunks were housed in two cages measuring $8 \times 8 \times 6 \frac{1}{2}$ feet high, located outside, on the roof of Science Building I at Portland State University, Portland, Oregon. The cages were constructed of $\frac{1}{2} \times 1$ inch mesh wire supported by a wooden frame. A slanted, green fiberglass roof afforded partial cover from rain and sun. The floor was covered with about three inches of fine wood chips, leaves, and sticks. Each cage had ten wooden nest boxes along one wall, with cotton available for nest material. Some of the nest boxes had no tops and were used by the chipmunks only for escape; the others contained a single entrance two inches in diameter. Several logs with branches were present, and a block of wood was attached to the wall of each cage. Water was available ad libitum in a single large trough in each cage. Food was placed in a small tin or scattered around the ground. Food was normally in abundance, but several times was withheld for a short period to study the effect of low food supply on agonistic 
behavior. Oatmeal made up the staple food during the study, but other items including raisins, nuts, watermelon seeds, and peanut butter were occasionally available. Most items that could be carried by the chipmunks were taken into the nest boxes or buried.

The chipmunks were caught in the southwest Portland hills by means of Sherman live traps baited with peanut butter. The area is one of steep slopes dominated by mature Douglas-fir trees (Pseudotsuga menziesii). The chipmunks were weighed, sexed, and toe-clipped for perminent identification. A patch of fur was dyed on each individual to allow for easy recognition of the chipmunks in the cages. I remarked the animals as necessary.

Observations were made through the window of a room situated three feet from the cages. Both cages were observed daily, but never simultaneously. Periods of observation varied from 15 to 60 minutes each, and were spread throughout the day between dawn and dusk. Yerger (1953) and Brand (I970) observed that chipmunks have two peak periods of daily activity in the wild; in this study their diurnal activity cycle was unpredictable. Activity became intense after the food tin was filled regardiess of conditions or time of day, even if more oatmeal was added to an elready abundant supply.

The periods of study for the cage groups varied from 
7 to 37 days. Since observation periods for each group were not uniform, agonistic confrontations are presented in this paper as encounters per hour for the purpose of comparison.

After the first month of observation, one chipmunk from each cage was moved to the other cage, thus creating two new groups of different membership. Twelve distinct groups were formed in this manner using the eight original chipmunks plus another captured late in October to replace one of the original subjects. By employing the same nine animals in 12 different combinations, the relationships between any two individuals was observed several times, but in the presence of different chipmunks. In addition, each chipmunk was observed in five to seven distinct social situations. This enabled comparison not only of agonistic behaviors and dominance hierarchies among cage groups, but provided data on the stability of pair relationships. Individual variations and some seasonal differences in frequency of agonistic encounters under various social conditions were also determined. One group of four animals studied in August was placed together again in December to compare behaviors.

In adaition to recoraing all agonistic encounters ( $N=6441$ ), all non-agonistic encounters ( $N=4298$ ) were recorded to investigate relationships between dominance and various other social behaviors. The type and 
participants of all encounters were recorded chronologically in the study, with observations separated by cage group. Dominance was deterrnined by analyzing encounters between each pair of individuals, with the animal who chased, threatened, or won a fight declared the winner. Chi-square tests were used to determine if the margin of victories over defeats was statistically significant (p<.01). If it was not, the two chipmunks were considered equals. Thus, dominance hierarchies were ascertained in each group, and the number of subordinate victories and switches in dominance investigated.

Variations in agonistic behaviors over a period of time were investigated. First, I attempted to determine whether changes in frequency, and/or frequency of types, of agonistic encounters occurred during the 7 to 37 day periods each cage group was together. Encounters during successive three day intervals were presented graphically. I also attempted to determine whether there were seasonal variations in agonistic behaviors between August and December. The total number and the number of each type of encounter during successive 15 day intervals were graphed, to detect any significant pattern in frequency of encounters from summer to fall and winter. 


\section{RESULTS}

\section{PATTERNS OF AGONISTIC BEHAVIOR}

I observed 10,739 encounters between captive E. townsendii; 6441 (59.9\%) were agonistic. Five types of agonistic behavior occurred-chases, fights, threats, displacements, and escapes.

\section{Chases}

Chasing was the most frequent agonistic behavior, comprising $58.5 \%$ of the total. Length of chases varied from a few feet or less to repeated swerving laps around the floor and wall of the cages. Speed of chase also varied. It was common for a dominant to chase a rival a dozen or more times in succession. One animal chased a rival 782 times in their period together without apparent waning of the tendency. The reaction of the subordinates, even to repetitive aggression, was a seeming absence of increased avoidance or isolation. Subordinates continually approached and were chased away by aggressive dominants. On other occassions, the subordinate did not withdraw from an approaching high-ranking animal. The latter then either attacked and chased the defiant chipmunk, ignored it, or approached and threatened or even 
nudged the subordinate into flight.

Chipmunks in this study most often engaged in chases without preliminaries ( $90 \%)$, but chases subsequent to fights or threats (10\%) also occurred. Only 13 of 3769 chases were initiated by subordinate individuals. Chase behavior normally began when a dorainant aninal, while exploring the cage, came upon a subordinate and immediately gave chase. Dominants did not appear to look for subordinates to chase. Chase was also elicited by the approach to a dominant of a subordinate. The latter usually began running before the dominant began to chase. Mhost chases ended with the dominant giving up and resurning other activities. Subordinate chases ended similarly, but were shorter. During these encounters, both participants ran with their tails straight out or slightly above parallel to the ground.

Fights

Fighting as used here included any physical contact of an apparently aggressive or hostile nature. Fighting in my E. towmsendii was infrequent (4.1\% of observed agonistic encounters) and of a mild nature. One hundred ten of the 261 fights involved two individuals grasping each other and tumbling about, while biting at and clawing each other. These bouts occurred when a dominant overtook a pursued subordinate, and lasted several 
seconds. Frequently the subordinate broke away, but sometimes the dominant did so immediately after catching the subordinate. This was particularly evident with WH, the alpha chipmuni of my study population, who would race to a nest box almost immediately after contact. Chasefight-chase sequences were also observed commonly (20\% of all fights).

A less frequent precursor to fighting was observed almost exclusively within the first few days I placed a group of chipmunks together, presumably when dominance hierarchies were being established. Two chipmunks would approach each other head-on until separated by a distance of approximately 10 centimeters. They would then chase each other in small circles, concluding with a fight. The preliminaries took only a few seconds, and although the bouts appeared more intense than usual, they still lasted only 3-4 seconds. The fight concluded with one chipmunk (victor) pursuing the other (Ioser).

Boxing (sparring with forefeet while standing exect on hind legs) occurred 67 times. This behavior occurred only after one chipmunk attempted to mount another. The normal procedure for the mounted individual was to move straight out of the grasp of the other, or occasionaliy to remain in a crouched position until the mounter gave up. In 67 of the 779 observed mountings (9.0\%), the animal on the bottom would turn, and, while both chipmunks 
were erect, strike with the forefeet its opponent's head and upper body. The other chipmunk would immediately retaliate in the same manner, using quick and repeated blows. In 60 of the 67 cases (88.0\%) the chipmunk initiating the boxing was dominant. No attempt to bite the opponent was evident, and the confrontations ended without further agonistic behavior.

Attacks resulted when a low ranked individual did not move when approached by an aggressive dominant (65 .: cases), or when a dominant caught another chipmunk by surprise (19 cases). These encounters involved the dominant striking with its paws and lunging at the subordinate, and/or biting at the subordinate, who would then withdraw, sometimes with the aggressor in pursuit. On a few occasions (5), when dominance was not yet established, an attack-withdraw-attack sequence was observed.

Threats

Four hundred forty one threats $(6.8 \%)$ were observed. Although chipmunk threat behavior is not highly stereotyped (Brand 1970 and Wolfe 1966), four forms of threat were recorded. Threats occurred in a variety of situations and involved many postures. A detailed analysis of postures was not atiempted. In the freeze threat, the threatening animal stares at its rival although the two animel's' bodies may be perpendicular to each other. Gen- 
erally, the threatening chipmunk's head is up, body straight or slightly arched, and tail straight out or up. Occasions of tail waving in a slow, up and dow or fast, jerky motion were observed, but were not a necessary component of the threat posture. Erection of the body hair was not noticeable, but tail hairs were slightly exected.

In the first few encounters, the threatened chipmunk would assume a position similar to that of the threatening chipmunk, and the two would exchange stares for up to 15 or 20 seconds. The distance between animals varied. On a number of occasions, the threatened or threatening individual would groom itself or turn in a different direction. Among chipmunks familiar with each other, a threat engendered a different reaction. A threatened subordinate either withdrew or turned its body and head down or perpendicular to the threatening dominant. It appeared that the crouched body position or turning away movement appeased the aggressor to some extent, for few chases occurred after this behavior. Another appeasement behavior was the lowering of the head or "bowing" when a superior approached or turned to face a subordinate chipmunk. Chases sometimes followed threats despite appeasement behaviors.

"Threat to chase" by a dominant involved quick, jerky movements toward a subordinate chipmunk that ended 
when the latter withdrew. The movement was accompanied by a thrusting forward of the head. On a number of occasions a dominant would bite at an opponent, or raise a foreleg and swipe at it even though the other chipmunk was well out of range. These actions were termed "threat to attack" and always caused a hasty retreat by the subordinate. Often the feet did not move at all in the behavior; only a forward thrust of the head and body occurred. Also, the foreleg was sometimes merely raised and not directed at the opponent.

A fourth type of threat, termed "turn threat", occurred when a subordinate approached an aggressive dominant from behind. The dominant, when it sensed the subordinate's approached, would turn its head rapidly to face to face the subordinate. This led to the subordinate's rapid retreat. The threat lasted only a brief interval, as did the chase and attack threats.

\section{Displacements}

Displacements took place when a low-ranking chipmunk relinquished its position to an approaching dominant, regardless of whether the latter appeared cognizant of its rival, and before any aggressive behavior took place. I observed 1971 ( $30.8 \%$ of agonistic encounters) displacements during the study. Displacement most often occurred at the food dish, the nost likely spot for two caged 
chipmunks to meet. The intensity of aggression between any pair was reflected by the distance from a dominant at which the subordinate withdrew; greatly harassed animals retreated earlier than more tolerant ones.

\section{Escapes}

Escape behavior in E. townsendii entails rapid runring away from any feared stimulus. The pattern of escapes of captive chipmunks was curious in that a rather elaborate chase-escape route was often employed which was navigated repeatedly until the chase stopped. Since most of the animals had places outside the nest boxes where they were most often found, the same routes of escape were observed a considerable number of times. Although E. townsendii are reported to be the most arboreal of their genus (Dalquest 1948 and Tevis 1956), most routes in the cages stuck to the ground or over objects on the ground. When a pursued chipmunk broke its pattern and climbed the side of the cage, it was rarely chased further. At other times, chipmunks spent a great deal of time climbing around the sides and also walking upside down across the ceiling of the cages. Agonistic behavior was rarely observed to occur from either position, even when intolerant chipmunks met. One animal (WT) developed an escape route that featured. running to a certain point, then turning suddenly and 
jumping directly over its pursuer and continuing in the opposite direction. Mlany of the subordinate chipmunks were seen running the same patterns alone that they often ran when chased. Other chipmunks were seen running routes with great repetition which they never used during a chase, and some, including the alpha chipmunk, never rain a discernable pattern.

\section{DOMINANCE HIERARCHY STRUCTURE}

All but one of my 12 cage groups established a stable, non-triangular hierarchy. Figures $I$ and 2 indicate the results of encounters in each group. Interactions between individuals in 16 of the 72 dyads did not justify designation of individuals as dominants or subordinates (p.01). A Iinear chase order could not be constructed for the nine chipmunks by combining the results of dominence relationships in the various fourmember hierarchies. Thus, to describe the hierarchies as strictly linear would be inaccurate.

Once established, dominance positions never changed in any one cage group. Dominance positions and hierarchical patterns did change, however, when a new chipmunk was added to a group. The highest and lowest ranks tended to be stable and predictable when chipmunks were relocated; the midale positions were less well defined. 
GTOUP $A(A 200-3 I)$

Winines:

\begin{tabular}{c|c|c|c|c|} 
& $\mathrm{RI}$ & $\because \mathrm{II}$ & $\mathrm{II}$ & $\mathrm{II}$ \\
\hline $\mathrm{RH}$ & $X$ & 2 & 3 & 0 \\
\hline $\mathrm{MI}$ & 6 & $x$ & 2 & 2 \\
\hline $\mathrm{ET}$ & 210 & 86 & $X$ & $I$ \\
\hline $\mathrm{NT}$ & 48 & 18 & 82 & $x$ \\
\hline
\end{tabular}

GrOUP $\mathrm{B}$ (Sept 1-14)

wininas.

\begin{tabular}{|c|c|c|c|c|}
\hline & UI & $\mathrm{RT}$ & $M$ & 0 \\
\hline$M I$ & $x$ & 0 & $I$ & 0 \\
\hline III & 42 & In & 3 & 0 \\
\hline $\mathrm{iTT}$ & 15 & 76 & $\dot{X}$ & 0 \\
\hline 0 & 156 & 77 & 238 & $X$ \\
\hline
\end{tabular}

Groul $\subseteq$ (Sept 25- Oct 8)

\begin{tabular}{|c|c|c|c|c|}
\hline & WIII & $\because 7-12$ & $\mathrm{WT}$ & 0 \\
\hline min & $X$ & 0 & 0 & 0 \\
\hline 152 & 24 & $\because$ & 9 & 0 \\
\hline WI & 36 & 7 & $\pi$ & 0 \\
\hline 0 & 293 & 14.0 & 324 & 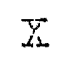 \\
\hline
\end{tabular}

GROUP A2 (AUE 8-3I)

rinnors

\begin{tabular}{|c|c|c|c|c|}
\hline & WH2 & YII & $\mathrm{HT2}$ & 0 \\
\hline WII2 & $x$ & 2 & 3 & 0 \\
\hline YH & 3 & $\mathrm{I}$ & 8 & 9 \\
\hline Wr2 & 5 & $I I$ & $X$ & $I$ \\
\hline 0 & 3 & 6 & 16 & $I$ \\
\hline
\end{tabular}

GROUP B2 (SeDt I-14)

$$
\text { wimers }
$$

\begin{tabular}{|c|c|c|c|c|}
\hline & RH & YH & 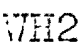 & WT2 \\
\hline PII & $\pi$ & 0 & 0 & 0 \\
\hline YII & 56 & $\pi$ & 0 & 0 \\
\hline VIH2 & 21 & 3 & $x$ & 0 \\
\hline Mr2 & 60 & 0 & 0 & $\pi$ \\
\hline
\end{tabular}

GROUP $\mathrm{C2}$ (Sept 15- 00t 6)

\begin{tabular}{|c|c|c|c|c|}
\hline & PII & $\mathrm{YH}$ & W2 & קוT \\
\hline$P H$ & $\bar{R}$ & 5 & $I$ & 0 \\
\hline$I E$ & 65 & $x$ & 2 & $I$ \\
\hline WT2 & 44 & 2 & $x$ & 4 \\
\hline 모 & $25 I$ & 226 & 34 & $X$ \\
\hline
\end{tabular}

Pisure 1. Results of aconigtic encoviters in six Froups öserved betreon August 1 and October 3,1972 . ifins ere recorded vertically and losses horizontelly. 
GOUP D (Oot S- IOV 15)

vinizors

\begin{tabular}{|c|c|c|c|c|}
\hline & $\mathrm{DHE}$ & $M I$ & $Y \mathrm{YII}$ & 0 \\
\hline $7 \mathrm{IIS}$ & $\bar{x}$ & 0 & 0 & 0 \\
\hline IIIT & 48 & $x$ & 5 & 0 \\
\hline YiI & 100 & 51 & $x$ & $I$ \\
\hline 0 & 375 & 247 & 777 & $X$ \\
\hline
\end{tabular}

GROUP E (NOV 15-22)

\begin{tabular}{c|c|c|c|c|} 
& WII & $\mathrm{XH}$ & $W \mathrm{~W} 2$ & 0 \\
\hline $\mathrm{III}$ & $\mathrm{X}$ & 0 & 0 & 0 \\
\hline $\mathrm{YH}$ & 28 & $\mathrm{X}$ & 0 & 0 \\
\hline $\mathrm{IT} 2$ & 6 & $I 8$ & $\mathrm{X}$ & 0 \\
\hline 0 & 100 & $I 76$ & $I$ & $\mathrm{X}$ \\
\hline
\end{tabular}

QI.OUD G (NOV 27- Dec 19)

\begin{tabular}{|c|c|c|c|c|}
\hline & $\mathrm{WII}$ & $\mathrm{BT}$ & 0 & $Y T$ \\
\hline $7 \mathrm{II}$ & $\ddot{I}$ & 0 & 0 & 0 \\
\hline $\mathrm{En}$ & 157 & $\pi$ & 0 & 0 \\
\hline 0 & 112 & 242 & $x$ & 2 \\
\hline YT & 135 & 224. & 50 & $X I$ \\
\hline
\end{tabular}

GrOUP D2 (Oct 9- iTOV 13)

\begin{tabular}{|c|c|c|c|c|}
\hline & FiF & $I T$ & .22 & TI \\
\hline RII & $x$ & $I$ & 0 & 0 \\
\hline $\mathrm{Rr}$ & 15 & $X$ & 1 & 0 \\
\hline$\pi 2$ & 13 & 10 & $X$ & $I$ \\
\hline Wrs & 30 & 27 & 27 & $r$ \\
\hline
\end{tabular}

GriOUP E2 (INOV I5-22)

\begin{tabular}{|c|c|c|c|c|}
\hline & DII & $R \Omega$ & II & WIIE? \\
\hline $\mathrm{RH}$ & $X$ & 1 & 0 & 0 \\
\hline $\mathrm{RP}$ & 51 & $X$ & 0 & 0 \\
\hline$W$ & $2 I$ & 8 & $I$ & 0 \\
\hline WI2 & 34 & 5 & 24 & $x$ \\
\hline
\end{tabular}

GPOUP I (Dec 19-3I)

\begin{tabular}{|c|c|c|c|c|}
\hline & $\mathrm{WH}$ & $R I$ & 淤 & PIT \\
\hline WII & $X$ & 0 & 0 & 0 \\
\hline $\mathrm{RH}$ & 21 & $\gamma$ & 3 & 0 \\
\hline $7 T$ & 27 & 25 & $z$ & 2 \\
\hline $\mathrm{RT}$ & 39 & 116 & 243 & $r$ \\
\hline
\end{tabular}

Pigure 2. Results of argonistic encounters in six Sroups obscrved betwoen October 9 and Deconioor 3I, 1972. Mins are recorded vertically and Iosses horizontally. 
The most marked alteration occurred in the relationship between RT and WT, both in the middle of the hierarchy. In the first four periods the pair was together, RT achieved a total of 193 wins in 197 agonistic encounters, chasing WT persistently and intensely during the initial two periods, and infrequently the last two. When placed together for the fifth and final time, at the end of the study, WT reversed dominance completely, winning 243 of 245 encounters.

A shift also occurred between the two alpha chipmunks in cage $A, \mathrm{BH}$ (maie) and $\mathrm{WH}$ (female). Placed together originally, the two were co-dominant, although $\mathrm{RH}$ was much more aggressive toward the other cage members. $\mathrm{KH}$ and WH lived in the same cage for a month with only eight displays of agonistic behavior between them; RH won six. The two were again placed together the last 15 days of the study; this time WH was clearly dominant. The number of confrontations was still small (2l), but WH won all. On eight other occasions when a pair of chipmunks was reunited, the relationship changed from that of equals to dominant-subordinate or from dominant-subordinate to equals. In all cases of equality (16), the number of agonistic encounters was minimal, ranging from 0 to 19 and averaging 7.0 . The rate of agonistic behaviors between equals was less than $8 \%$ of the average encounter frequency $(28.0$ per hour) during the study. 
In group A2, in which no dominance hierarchy was discernable, the overall average encounter rate was 4.8 per hour, compared with 21.9 agonistic encounters per hour in group A (observed at the same time). Furthermore, the rate in A2 after the first day diminished to 1.8 per hour for the rest of the month. Five of the six dyad relationships in $A 2$ were labeled equal rather than dominant-subordinate $(p>01)$. The other relationship, though dominant-subordinate $(p<.01)$, was comprised of only 17 encounters, 16 won by the dominant.

Dominance hierarchies within each group were extremely stable. Of 6329 agonistic encounters between dominant-subordinate dyads, $42(0.7 \%)$ subordinate victories were recorded. Subordinate wins were not confined to the first few encounters, but were dispersed throughout the periods the groups were together. Subordinate victories included 15 displacements, 13 chases, and 5 threats. No "grasp-and-tumble" fights were lost by dominants, but subordinates twice attacked higher ranked individuals, and seven times initiated, and were successful in, boxing with superiors.

Sex And Size Relative To Rank

Only one hierarchy existed for both sexes, and rank was irrespective of sex. Although size was of some importance in determination of rank, neither weight nor length were sufficient to explain the establishment of hierarchy 
position. It was cormon for a much lighter chipmunk to dominate or achieve equality with a larger one. WH2, a female weighing 112 grams, was the heaviest chipmunk, yet did not dominate in any of the five groups in which she was observed. WT2, on the other hand, who weighed 78 grams, was equal with YH $(97 \mathrm{gm}), O(83 \mathrm{gm})$, and $W H 2$, and dominated RT $(94 \mathrm{gm})$ and WT $(95 \mathrm{gm})$.

Territoriality

No territorial behavior was evident among my $\underline{E}$. townsendii. The nest boxes were not even defended. On a number of occasions, three chipmunks were found together in a single nest box. As some of these observan tions were made in Auguist:at temperatures of $24^{\circ} \mathrm{C}$, aggregation for warmth is a tenuous explanation for the observed lack of territoriality. At the food tin, chipmunks that were normally tolerated by the dominants were allowed to feed alongside them. In one cage, where tolerance between all four chipmunks was realized, the animals were seen climbing all over each other trying to get at the oatmeal in a small tin. Several times food was withheld for a short time; this brought varying results. In the groups where all were tolerant of each other, and in other instances where two or more animals were equals, agonistic behavior was absent despite apparent hunger. At other times, a dorinant chipmunk chased subordinates more intensely than usual, and even chased chipmunks 
normally tolerated. The chases usually did little to deter a hungry subordinate from approaching the food repeatediy after it was replaced, only to be chased away each time. Iow-ranking animals approached the food dish in a cautious manner, creeping up with their bodies low, even if the dominant was not near. Since an abundant local supply of food is probably the principle occasion for chipmunis to encounter each other in nature, the apparent wariness around food is likely due to past experience. Most feeding is done away from the food tin. An animal would fill its cheek pouches with food, depart to cache or eat it, then return and repeat the procedure.

\section{Residence}

Among many species of animals, the resident of a cage has an advantage in conflicts with a new arrival, presumably because the introduced animal is comparable to an intruder in an already established territory (Tinbergen 1965). I did not observe this relationship among my chipmunks. In the first change of combinations, RH, a co-dominant with WH in Group $A$, was placed in the other cage with three animals that had been housed there for the previous month. Shortly, and with a minimum of resistance, $\mathrm{RH}$ assumed the dominant role in his new cage. 0 , conversely, became the lowest subordinate in cage I. In the next change, newly introduced WH2, a dominant, lost a 
brief but intense struggle with $W H$ for dominance, and assumed equality with and dominance over the two other cage members. In general, determination of rank following regrouping was not influenced by previous rank.

One effect of the introduction of a new arrival into a cage of three residents was an increase in level of agonistic encounters among the residents. Anong chipmunks between whom conflict had ceased or greatly subsided, sometimes for weeks previously, the actively dominant-subordinate roles resumed. Subordinates who had freely approached dominants or equals resumed cautious and hesitant manners, and approached the dominants or equals less frequently. A chipmunk with little fear of another approached with a steady, but jerky movement with the body in a normal walking position. The more fearful animals approached using a slower, more creeping movement with the body stretched out and low to the ground. Ample opportunity was available to observe the latter. since even the most intensely chased subordinate occasionally approached a dominant. Less intensely chased subordinates approached frequently, usualiy with nose-to-anal or nose-to-nose postures, as if to seek tolerance of the dominant.

No mortalities due to fighting occurred in the five months of the study. Two animals died near the 
end of the study from unknown causes. No wounds were visible on any chipmunk throughout the study but tail hairs of some individuals were nipped off during chases. The fur of subordinates was noticeably rougher than that of dominant animals, particularly on chipmunks chased frequently. No patches of fur were pulled out however.

Encounters Versus Rank

The relationship between number of agonistic encounters and social rank was investigated by comparing the total number of wins and losses for each animal to the others in the group. In 7 of the 12 cage groups, the lowest subordinate was involved in the most encounters and never was least involved. The alpha chipmunk, on the other hand, was involved in the most encounters in only two cage groups and was least involved in three. The dominant animal had the most total victories in half of the cage groups.

The chipmunk hierarchies I studied did not conform to the observations of other workers that closest rivals fight most frequently and intensely (Anthony 1955; Bronson 1964; Wolfe 1966). $\mathrm{RH}$ and $\mathrm{WH}$, alpha chipmunks in group $A$, fought with RT and WT, the third and fourth-ranked individuals, far more than with each other. In group B, the dominant (WH) chased 
fourth-ranked 0 approximately three times as often as the two intermediate rivals combined. In all but two cage groups, the dominant chased the lowest subordinate with equal or greater frequency than the others. Second-ranked individuals also chased the lowest subordinate equaliy or more frequently than the third-ranked animal. Dominants chased second and third ranked individuals approximately equally. Such a chase structure reveals the reason for the high number of agonistic encounters participated in by the lowest subordinate. My observations indicate that the number of chases between individuals is a reasonably good indication of the intensity of aggression.

\section{HIERARCHY DEVELOPMENT}

Establishment And Stereotypy

As indicated previously, the establishment of a hierarchy among captive E. townsendii is swift, stable, and permanent within any group. The adaptive advantage of the hierarchy with regard to reducing fighting and chasing, however, is minimal or at least unpredictable. The combination of ritualization and appeasement, typical of many species and resulting in a predominance of threat behaviors to maintain dominance, is not seen in E. townsendii. Serious chases and fights continued through the duration of each cage period between some 
pairs of chipmunks with no deterioration of intensity in later stages of interaction.

Establishment of a clear dominance order took varying lengths of time and numbers of encounters, but never more than six or seven confrontations between any two individuals. A common sequence of events was one or more nose-to-anus meetings, followed by two or three attacks or fights. Thereafter, chases and displacements becane the principle agonistic behaviors with a dominant and subordinate role clearly defined. The rapidity of this formation accounts in part for the extremely low number of subordinate victories recorded in the study. No chipmunk was observed to turn and defend itself after a chase began. In a number of cases, a relationship was established without conflict. That is, a chipmunk placed in a cage with three others would chase or be chased with no preliminary fighting, threatening, or recognitory behaviors.

In-group Agonistic Behavior Through Time

A graphic analysis of the number of agonistic behaviors through time in each cage group produced mixed results. The classical decrease of encounters through time was seen in several cages, but was generally absent or indistinct. Figures 3 and 4 illustrate the pattern in nine cages where observations were lengthy and broad 



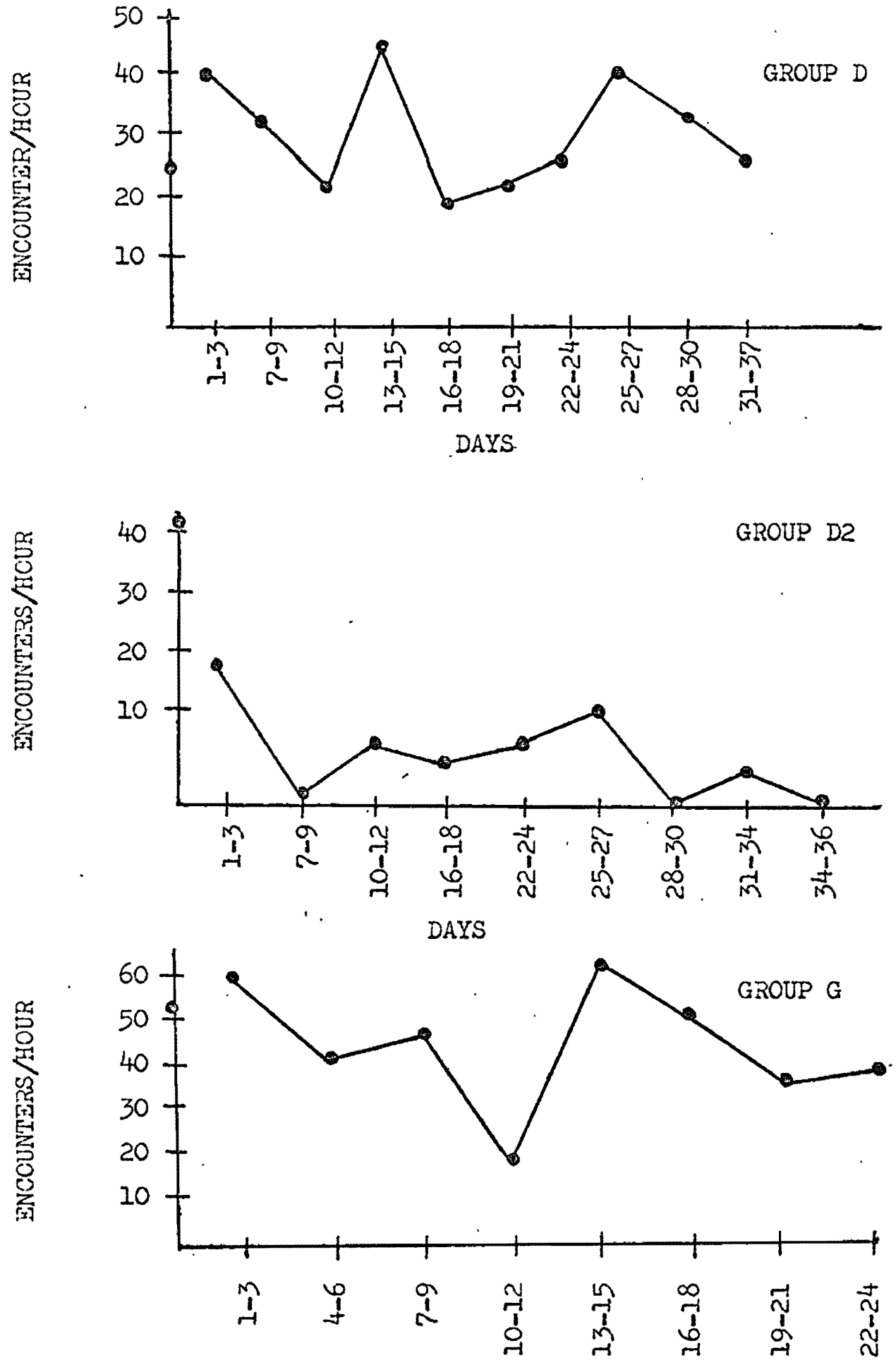

DAYS

Figure 4. Frequency of agonistic encounters through time in three cage groups observed between October 9 and December 19,1972. The dot on the ordingte represents the encounter rate for the iirst day the group is together. 
enough to produce a clear representation.

Cage A shows a general trend toward increased agonistic behavior, while groups $\mathrm{B} 2$ and $\mathrm{C} 2$ show a general decrease with time. Groups $B, C, D$, and $G$ show fluctuating levels of agonistic encounters, but no trena either to decrease or increase. Groups A2 and D2 show an initially high rate of encounters (particularly emphatic when the first day's average is considered), followed by a sharp drop and subsequent relative stability at a low average frequency. Taking the agonistic behaviors in each interval from all the cages together, the curve somewhat resembles a normal extinction curve (Figure 5).

To reveal any changes in percentages of types of agonistic behaviors through time in each cage, threats, chases, displacements, and fights were separately tabulated in successive four or five day intervais. No significant change or trend was evident between initial and later intervals, with the number of threats remaining. low, and chases remaining proportionally much higher.

\section{SEASONAL VARIATION}

Despite the tendency for E. townsendii to hibernate from late autumn to early spring (Walker 1923; Anthony 1924; Tevis 1966), my caged animals remained active throughout the study. Mioreover, despite an un- 


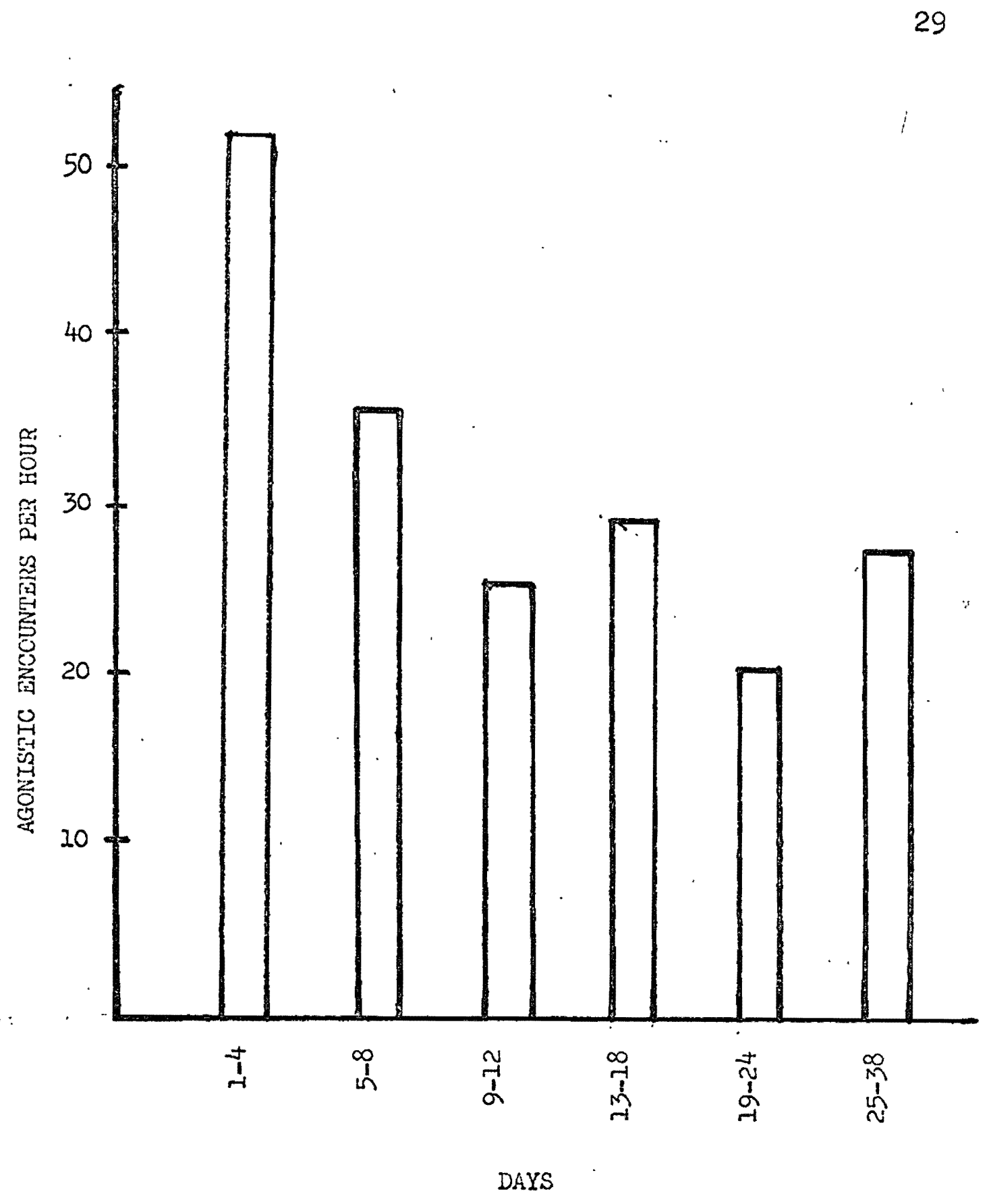

Figure 5. Total agonistic encounters in all cages during successive time intervals 
usually cold December when temperatures remained below freezing for two weeks and reached $-5^{\circ}$ to $-10^{\circ} \mathrm{c}$, the greatest frequency of agonistic encounters occurred in November and December. A graph showing the total number of agonistic encounters through time (Figure 6) suggests a general increase in agonistic encounters from August to December, with a peak in september surrounded by lower periods in August and October.

The lowest frequency of agonistic encounters was during August when temperatures averaged near $27^{\circ} \mathrm{C}$. My results suggest a pattern of seasonal variation in agonistic encounters among the chipmunks in this study. Non-agonistic and agonistic behaviors combined averaged approximately 39 per hour in August in contrast to 47 for September, 49 for both October and November, and 52 for December.

Figure 7 shows variations in type of agonistic behaviors in my study, with each point on the curve representing the average over a 15-day period. A great number of threats occurred during August relative to later months. Only during the first month did threats approach the number of displacements, actually surpassing the latter during the first 15 days. Threat frequency diminished during September, and persisted at a relatively stable, low level for the remainder of the study. Fighting declined after August and remained at a low 




Figure 6. Seasonal variations in overall agonistic encounters (average encounters per hour in successive 15 day intervals). 




Figure 7. Seasonal variation in frequencies of four types of agonistic behaviors in Successive 15 day intervals. 
level throughout the rest of the study. After an initial sharp rise in both chases and displacements, the two curves appear almost as mirror images of each other. Groups $A$ and H, observed during August and December respectively, contained the same combination of four chipmunks. In addition to two dominance changes mentioned earlier, agonistic behavior in December was considerably greater. Overall, the frequency of agonistic encounters more than doubled, from 21.9 per hour to 43.3 . Non-agonistic behavior remained at comparable levels (17.8 and 23.4). The total intraspecific activity (frequency of all encounters) was 39.7 per hour in August and 66.7 in December. The change in types of agonistic behaviors was marked, with threats diminishing from $22.1 \%$ to $1.6 \%$ and chases increasing from $46.0 \%$ to $68.4 \%$. Displacements and fights were similar in the two groups.

\section{$V$ INTERGROUP AND INDIVIDUAI VARIATION}

Frequency of agonistic encounters varied a great deal among cage groups, even when observed during the same period (Figure 8). The range of frequencies of agonistic encounters in the 12 cage groups was 4.8 per hour to 43.9 per hour. The total average for the study was 28.0 agonistic encounters per hour ( $N=6441, I=230$ hours). Frequencies of the four types of agonistic behavior also varied widely among individual cage groups. 




Figure 8. Frequency of àgonistic encounters in 12 cage groups. 
Threats comprised from $0.9 \%$ to $31.3 \%$ of the total agonistic encounters and chases from $31.3 \%$ to $73.5 \%$. Displacements made up between $14.9 \%$ and $40.1 \%$ of the totals and fights between $0.6 \%$ and $23.4 \%$.

Non-agonistic encounters tended to be higher in groups with low agonistic behavior frequencies. The highest average number of non-agonistic encounters $(47.7 / \mathrm{hr}$.) occurred in group D2, where only 7.8 agonistic encounters per hour were recorded. The lowest frequency of non-agonistic encounters (1.8) was observed in group $G$, where the highest frequency of agonistic behaviors occurred. The possibility of high agonistic and non-agonistic behaviors occurring together is enhanced in a cage where both tolerance and dominant-subordinate relationships exist. This happened in group $H$ where 25.4 non-agonistic encounters per hour in addition to 43.9 agonistic encounters produced a total rate of 66.7 per hour.

A great deal of individual variability in behavior was apparent during the project. Some chipmunks were clearly more aggressive than others. WH, the alpha chipmunk in the study, was the least frequently observed out of the nest box and least disposed to chase. In its initial cage experience, WH showed tolerance toward two conspecifics and chased the other only sparingly. $\mathrm{RH}, \mathrm{a}$. co-dominant in that cage, engaged in over 2.4 times as many agonistic encounters. In its next group however, 
WH recordea over twice as many agonistic behaviors in $25 \%$ less time.

WH was in some ways the most timid of the subjects, taking considerably longer to come out after a disturbance than the others. WT2 and 0 , on the other hand, were a good deal less timid than the others. WT2 approached me closely enough to eat from a held tin or knife, while even two months later, others still retreated hastily to the nest boxes when I approached the cage. 0 and WT2, curiously, occupied two of the three lowest positions in the hierarchy. 


\section{DISCUSSION}

Although primarily solitary, chipmunks have widely overlapping ranges and are found to aggregate in places where local food supplies are abundant or preferred (Gordon.1943; Yerger 1953; Dunford 1970). Thus, a dominance hierarchy to minimize fighting and chasing would be of selective advantage. Observations of E. townsendii revealed the existence of a rapidly formed, stable hierarchy. Figures 3 and 4 show that agonistic behaviors in the various cage groups generally do not follow the pattern of gradual extinction. Further, Figure 7 shows that a transition from fighting and chasing to threat and displacement is not realized. Threats were very few and not highly stereotyped, perhaps due to the chipmunk's relatively solitary existence, and consequently effectiveness was inconsistent. A threat rnust be easily recognized as such if it is to be effective. Although indiviaual recognition and memory are achieved, the escape and avoidance drives are insufficient to reduce encounters to a low level, and not appreciably intensified even by repeated chases. Habituation for chasing did not occur in relationships between some pairs. My data suggest a number of possible explanations 
for the selective advantage of dominance hierarchy in chipmunks. First, the relatively rare occasions of fighting compared to other patterns of agonistic behavior is of some advantage (Figure 7). Visible injury never occurred in the fights I observed, and field work (Broadbooks 1958; Brand 1970) indicated that few serious injuries occur in natural Eutamias populations. Tolerance or severely curtailed agonistic behavior, rather than intense conflict, was manifested in equals. Only in clear-cut dominance-subordinate relationships did a great deal of agonistic behavior exist. Since these encounters involved either chases or displacements, in which escape was nearly certain, few serious confrontations arose. Escape in wild populations, particularly with Ex townsendii, which inhabit forested areas, is almost ensured. Agonistic behavior of dominant chipmunks is not confined or even focused on one member of the hierarchy, often the top subordinate in other animals, but is spread throughout, thus reducing intense pair conflicts. Furthermore, the seeming inhibition of fighting in Eutamias may be another check against physical damage. Another advantageous consequence of dominance is that the strongest and most fit animals have access to preferred mates and locally short supplies of food. Agonistic behavior in general also serves for dispersal, protection of young, and population control (Sheppard and 
Yoshida 1971; Broadbooks 1970; Steiner 1972).

Another function of agonistic behavior in Eutamias is to competitively exclued other species in areas of overlap. Heller (1970) found that $E_{\text {. }}$ amoenus and E. alpinus, by virtue of their more aggressive natures, exclude E. speciosus and E. minimus from areas included in the latter two animals' fundamental niches. The result is an altitudinal zonation of species. Brown(1971) and Sheppard (1971) found similar exclusions of less aggressive Eutamias by more aggressive ones. Aggressive exclusion does not always occur, however. Broadbooks (1970) and Dalquest (1970) found E. amoenus feeding alongside E. minimus and E. townsendii respectively. The chipmunks in my work are the only species of Eutamias in the area.

The failure of chipmunks to avoid confrontations with dominants even after severe chasing has a selective advantage for subordinates, particularly where food is concerned. Ify study confirms other work (Fraleigh 1929; Wolfe 1966; Brand 2970) in asserting that food is the focal point of agonistic behavior in natural populations and its presence engenders aggression. Iow-ranked individuals, dominated at a preferred food source, approach incessantly, regardless of intensity of chase or location. In caged Eutamias, only one feeding area was present, and subordinate approaches were common. Wolfe (1966) found that chasing did not reinforce the escape drive in 
captive Tamias either. The most intense agonistic behavior is often associated with food.

Field studies show that hierarchies appear to be less stable in wild populations of chipmunks than in captive groups (Gordon 1943; Brand 1970; Dunford 1970). The primary reason for the instability is the disorganization that arises with the departure and arrival of different or new chipmunks in addition to the consistent presence of different combinations of individuals. Mity work indicates that both frequency of agonistic behavior and reversals of dominance are affected by establishing new groups. Brand (1970) stated that when a great number of chipmunks assembled, reversals were frequent. Presumably this was due to the inability to recognize individuals. In captive chipmunks, recognition plus stability of groups resulted in stability of hierarchy and infrequency of reversals.

Changing combinations of chipmunks in cages demonstrated concentrated aggression toward a new animal by the dominant, and a general increase in overall agonistic behavior incluaing intensification in the established relationships among other chipmunks in the cage. Subordinate animals that were tolerated for weeks previously were suddenly chased vigorously. Animals such as wH were much more aggressive in some cage: groups than in others. WH, for example, initiated an average of 5.2 agonistic 
encounters in group $A$, then averaged 14.2 encounters in the next group (B) with only one change made. The makeup of the group, then, is important in determining the level of agonistic encounters. Figure 8 demonstrates the wide range of agonistic encounters in the 12 cage groups (4.7-43.9 per hour).

Seasonal variations, although much less a factor in level of agonistic behavior, may exist as indicated by Figure 6. Gordon (1943) and Yerger (1953) observed that the peak of agonistic behavior in wild ramias occurred in late september and early October, declining thereafter. Brand (1970) reported a marked decrease in winter aggression among Eutamias, although the number of encounters did not decrease. Wolfe (1966) found a greatly reduced number of chases in T. striatus in July, and postulated a pattern of seasonal variation in that species. Ny results suggest a similar depression in overall agonistic behavior and activity during the late surmer, followed by a peak period in September. Summer abundance of food and high temperatures, followed by increased drive to store quantities of a diminishing supply of food are likely involved in this pattern. The failure of my chipmunks to decrease activity or hibernate as winter approached vas perhaps due to the artificially constant food supply or other results of captivity.

The existence and importance of individual differ- 
ences in agonistic behavior of chipmunks was observed both qualitatively and quantitatively in my study. Broadbooks (1958) asserted that individual differences in temperament of young E. amoenus were marked by the end of the first month. Fraleigh (1929), Cordon (1943), and others have reported an extreme variability in timidity, activity, aggressiveness, and temperament in other species of chipmunks. Although size appears to be the best physical determinant of rank, it is supplanted repeatedly by individuality. Causes for this may be different thresholds for eliciting agonistic behavior, variations in endocrine output, genetic variations, age, and past experience. The relative inportance of experience in: determining rank or aggressiveness is unknown in natural populations, but captive E. townsendii show a considerable effect of conditioning. This is exemplified by many instances in which a dominant-subordinate relationship is established without prior conflict, with the dominant assuming the role of chaser and the subordinate taking the opposite role. Extinction of the escape drive in very low ranking chipmunks is very slow.

Despite the general persigtence of agonistic behaviors, such interactions between some pairs decreased to the point of infrequency or extinction. Subsequent encounters between these animals were predominantly recognitory or sexual. In most interactions following this 
pattern, conflicts waned within three days. Others persisted several more days at a high level before dropping appreciably. An increase in agonistic encounters with time was also observed in a number of pair relationships. Individual recognition is the key to establishment of a dominance hierarchy. It has been mentioned before that some subordinates are not chased at all, while others are chased consistently and vigorously. The great number of displacements recorded indicates recognition to the point of awareness of rank with respect to an approaching chipmunk. The response to the approach of an equal, tolerant dominant, or subordinate is quite distinct from response to an aggressive dominant. The consistency of dominant victories $(99.3 \%)$ relates in part to the efficiency of the mechanism for recognition. A behavior often recorded was the continuation of a dominant's chase from a subordinate normally harassed to one who was rarely, if ever, chased under other circumstances. In most of these instances, the dominant merely chased the tolerated chipmunk a few feet, and frequently touched noses immediately. A number of times, a dominant who started to chase a tolerated conspecific stopped abruptly as if the chased animal was then recognized. Regarding dominant-subordinate relationships in general, the proximity of another animal was not always a sufficient stimulus for agonistic behavior, nor was a particular 
size, sex, or rank.

Lack of quantitative studies limits comparison of the structure and development of agonistic behavior in E. tounsendii to those in other sciurids, but dominance hierarchies, with the exception of Cynomys, are similar in generally lacking strict linearity in natural populations, in demonstrating relative stability and infrequent reversals, and in using avoidance or escape as primary methods of minimizing injurious encounters. Agonistic behavior in the family Sciuridae varies from Spermophilus columbianus(Steiner 1972) and S. townsendii (Alcom 1940), in which severe injuries and fights occur often, to Glaucorgys sabrinus which is highly sociable (Burt 1940). Dominance hieraxchies range from virtual absence in highly territorial sciurids where physical contact is rare, such as Tamiasciurus (Smith 1968) and S. fremontii (Gordon 1936), to the well-defined and peaceful hierarchy of Cynomys (King 1951 and Anthony 1955). "Stereotypy and ritualization are much more developed in Gynomys and many ground squirrels than in chipmuniss (Sheppard and Yoshida 1971; Yeaton 1972) or in genus Marmota (Bronson 1964; Armitage 1965). Although my chipmunks groomed meticuously and persistently, no social grooming was apparent. Appeasement behaviors, relatively common in other sciurids (King 1951; Bronson 1964; Steiner 1972; Yeaton 1972), were undeveloped in E. townsendii, presumably because 
escape and avoidance are employed almost exclusively in naturaI populations to regulate aggression. I reported several appeasement behaviors in captive chipmunks, but their use was sporatic and their effectiveness marginal.

Although the similarity between Eutamias and Tamias is marked, several differences occur in comparing the two genera. The intensity of agonistic encounters and occurrences of wounds and mortality due to fighting is much less (absent in my work) in E. townsendif (Dalquest 1948). Broadbooks (1970) observed repeated fighting and chasing in E. amoenus without fatalities. Interspecific fighting among Eutamias species was usually brief in the field, but often more severe in the lab (Brand 1970). Wolfe (1966) reported 11 mortalities and several other crippling injuries due to fighting in caged Tamias, and Condrin (1936) observed "invariable death" when two T. striatias were confined together. Subordinate E. townsendii engage in considerably more agonistic encounters, and chases by dominants are spread out over the entire hierarchy more evenly. Wolfe (1966) correlated higher numbers of encounters with closeness of rank in Tamias, and found a correlation between rank and number of agonistic behaviors participated in. Neither were the case in my study. Subordinate victories occurred with four times the frequency (3.1\%) in Wolfe's (1966) study of Tamias. 
Patterns of agonistic behavior, hierarchy structure, and overall frequency of types of agonistic behavior were highly comparable in eastern and western chipmunks. Chases were the most comon agonistic behavior in captive Tamias (Wolfe 1966; Dunford 1970) as in my Eutamias, and made up a percentage of total observed agonistic behaviors comparable to that in my study. The percentage in Brand's (1970) study of Eutamias was also similar. Fighting in captive Tamias (Ferger 1953; Wolfe 1966) was more frequent than in my study, but began and ended similarly. Comparable threats were also reported for Tamias and for other species of Eutamias (Brand 1970). Further study of agonistic behavior and dominance in western chipmunks would perhaps be most beneficial in the area of quantitative field work with natural populations to augment the present study on captive animals. In addition, comparative studies of the 16 species of Eutamias, relating social behavior to habitat, range, and other natural history information, would delineate more clearly the ecological significance and developmental history of dominance and agonistic behaviox in the genus. 


\section{CONCIUSIONS}

1. Dominance hierarchies in E. townsendii are not effective in substantially abating agonistic behavior.

2. Initiation of agonistic behavior is affected by a combination of factors including hunger, season, individual differences in disposition, the presence of unknown animals, disorganization of the hierarchy, and (perhaps most importantly) the reaction of the subordinate.

3. Experience and individual differences in activity and aggressiveness are nore important determinants of rank than either sex or size.

4. Residence is of no significance in intraspecific encounters among chipmunks.

5. Food is the focal point of agonistic behavior and its presence engenders aggression.

6. Repetitive chasing did not reinforce the escape drive in subordinate chipmunks.

7. Disorganization of a hierarchy and unfamiliarity results in an increase in agonistic behavior and in reversals of dominance. Extreme hierarchical and dominance stability is a result of recognition within a stable 
group.

8. Dominance in E. townsendii, although ineffective in reducing time and energy losses through chasing, offers a selective advantage by curtailing serious confrontations, and in some cases enhancing the establishment of tolerance between individuals. 


\section{REFERENCES}

Ackerman, $R$. and P.D. Weigel. 1970. Dominance Relations of Red and Grey Squirrels. Ecology, 51: 332-334.

Alcorn, J.R. 1940. Iife History Notes of Piute Ground Squirre1. J. Marm., 21: 160-170.

Anthony, A. 1955. Behavioral Patterns in a Iaboratory Colony of Prairie Dogs, Cynomys Iudovicianus. J. Mamm., 36: 69-78.

Anthony, A.W. 1924. Hibernating Chipmunks. J. Mamm., $5: 76$.

Armitage, K. 1965. Vernal Behavior of the Yellow Bellied Marmot (Marmota flaviventris). Animal Behav., $13: 59-68$.

Balph, D.F. and A.W. Stokes. 1963. On the Ethology of a Population of Uinta Ground Squirrels. Amer. Midland Nat., 69: 106-126.

Brand, I.R. 1970. Vocalizations and Behavior of Chipmunks in California. Ph. D. Thesis, Cornell Univ., $128 \mathrm{pp}$.

Broadbooks, H.E. 1958. Iife History and Ecology of the Chipmunk, Eutamias amoenus in Eastern Washington. Misc. Publ. in Z001., Univ. of Michigan, no. 103, $42 \mathrm{pp}$.

Broadbooks, H.E. 1970a. Home Range and Territorial Behavior of the Yellow-Pine Chipmunk, Eutamias amoenus. J. Mamm., 51: 310-326.

Broadbooks, H.E. 1970b. Populations of the Yellow-Pine Chipmunk: (Eutamias amoenus). Amer. Midland Nat., $83: 472-488$.

Bronson, F.H. 1964. Agonistic Behavior in Woodchucks, Animal Behav., 12: 470-478.

Brown, J.H. 1971. Mechanisins of Competitive Exclusion Between Two Species of Chipmunks. Ecology, 52: 305-311. 
Burt, W.H. 1940. Territorial Behavior in Populations of Small Mammals in Southern Michigan. Misc. Publ. Ifus. Zool., Univ. of Bifich., no. $45,58 \mathrm{pp}$.

Carl, E.A. 1971. Population Control in Arctic Ground Squirrels. Ecology, 52: 395-413.

Condrin, J.M. 1936. Observations of Seasonal and Reproductive Activity of Eastern Chipmunks. J. Mamm., 17: $231-234$.

Dalquest, W.W. 1948. Niammals of mashington. Univ. of Kansas publ. Mrus. of Natural History, Lawrence, Kansas, 2: 444 .pp.

Dunford, C. 1970. Behavior Aspects of Spatial Organization in the Chipmunk, Tamias striatus. Behavior, 36: 215231.

Farentinos, R.C. 1972. Social Dominance and Hating Activity in the Tassel-Eared Squirrel (Sciurus aberti ferreus). Animal Behav., 20: $3 \overline{16-326 .}$

Forbes, R.B. and I. Turner. 1972. Notes on Two Iitters of Townsend's Chipmunks. J. Mamm., 53: 355-359.

Fraleigh, I.B. 1929. The Habits of Mammals at an Adirondack Camp. N.Y. State His.s. Handbook, no. 8: II9167.

Gordon, K. 1936. Territorial Behavior and Social Dominance among Sciuridae. J. Mamm., 17: 171-72.

Gordon, K. 1938. Observations of the Behavior of CalloSpermophilus and Eutamias. J. Niamm., 19: 78-84.

Gordon, F. 1943. The NaturaI Higtory and Behavior of the Western Chipmunk and the Miantled Ground Squirrel. Oragon State Monographs in Zool., 5: 1-104.

Heller, Horace. 1970. Altitudinal Zonation of Chipmunis: Interspecific Aggression, Water Balance, and Energy Buagets. Ph.D. Thesis, Yale Univ., 112 pp.

Howell, H.H. 1929. Revision of the American Chipmunks. North American Fauna, no. 52: 1-157.

Kilham, I. 1954. Territorial Behavior of the Red Squirrel. J. Hamm., 35: 252-253. 
King, J.A. 1951. Social Behavior, Social Organization, and Population Dynamics in a Black-Tailed Prairie Dog Town in the Black Hilis of S. Dakota. Ph.D. Thesis, Uaiv. Of Mich., 329 pp.

Nieredith, D.H. 1972. . Subalpine Cover Associations of Eutamias amoenus and Eutamias townsendii in the Washington Cascades. Amer. Midland Nat., 88: 348357.

Peck, J.C. 1967. Influence of Social Hierarchy on Gray Squirrel Behavior. J. Wildiife Migmt. 31: 720-728.

Quanstrom, W.R. 197I. Behavior of Richardson's Ground Squirrel. Animal Behav., 19: 646-652.

Reilly, R.E. 1972. Pseudo-Copulatory Behavior in Eutamias minimus in an Enclosure. Amer. Midland Nat., 88: 232 .

Sheppard, D.H. 1971. Competition Between Two Chipmunk Species (Eutamias), Ecology, 52: 320-329.

Sheppard, D.H. and S.M. Yoshida. 1971. Social Behavior in Captive Richardson's Ground Squirrels. J. Mamm., 52: 793-799.

Smith, C.C. 1968. The Adaptive Nature of Social Organization in the genus of Tree Squirrels (Tamiasciurus). Ecological Monog:, 38: 31-62.

Steiner, A.I. 1972. MortaIity Resulting from Intraspecific Fighting in some Ground Squirrel Populations. J. Mamm., 53: 601-603.

Taylor, J.C. . 1966. Home Range and Agonistic Behavior in the Grey Squirrel. Symp. Zool. Soc. Iond., I8: 229-235.

Tevis, I. 1956. Responses of Small Mammal Populations to Iogging in Douglas-fir Forests. J. Hamm., 37: $189-196$.

Tinbergen, N. 1965. Social Behavior in Animals. Wiley and Sons, in., $150 \mathrm{pp}$.

Walker, A. 1923. Notes on the Winter Habits of Eutamias townsendij. J. Miamm., 4: 257.

Warner, G.IH. 1971. Vocalizations of the Townsend Chipmunk (Eutamias townsendii). MI.S. Thesis, Portland State Univ., 37 pp. 
Wolfe, J.I. 1966. Agonistic Behavior and Dominance Relationships of Eastern Chipmunk, Tamias striatus. Amer. Pilidand Nat., 76: 190-200.

Yeaton, R.I. 1972. Social Behavior and Social Organization in Richardson's Ground Squirrel (Spermophilus richardsonii) in Saskatchewan. J. Ramm., 53: $139-147$.

Yerger, R.W. 1953. Home Range, Territoriality, and Populations of the Chipmunk in Central Mew York. J. Hamm., 34: 448-458. 